\title{
Population pharmacokinetics and dosing of milrinone after patent ductus arteriosus
}

\section{ligation in preterm infants}

Maarja Hallik, MD²,; Mari-Liis Ilmoja, MD²; Tõnis Tasa, MSc³; Joseph F Standing, PhD; Kalev

Takkis, PhD5; Rūta Veigure, MSc6; Karin Kipper, $\mathrm{PhD}^{5,6}$; Tiiu Jalas, MD²; Maila Raidmäe, MD²;

Karin Uibo, MD²; Joel Starkopf, MD, $\mathrm{PhD}^{1,7}$; Tuuli Metsvaht, MD, $\mathrm{PhD}^{7,8}$

1 Department of Anesthesiology and Intensive Care, Institute of Clinical Medicine, University of Tartu, Tartu, Estonia

2 Clinic of Paediatrics, Tallinn Children's Hospital, Tallinn, Estonia

3 Institute of Computer Science, University of Tartu, Tartu, Estonia

4 Inflammation, Infection and Rheumatology section, Great Ormond Street Institute of Child Health, University College London, London, United Kingdom

5 Analytical Services International, St George's University of London, Cranmer Terrace, London, SW17 0RE, United Kingdom

6 Institute of Chemistry, University of Tartu, Tartu, Estonia

7 Clinic of Anaesthesiology and Intensive Care, Tartu University Hospital, Tartu, Estonia

8 Department of Pediatrics, Institute of Clinical Medicine, University of Tartu, Tartu, Estonia

The study was performed at Tallinn Children's Hospital, Tallinn, Estonia and Tartu University Hospital, Tartu, Estonia.

Financial support: Estonian Research Council (PUT1197).

Keywords: Milrinone; Pharmacokinetics; Preterm Infants; Patent Ductus Arteriosus; Low Cardiac Output

Corresponding author: Maarja Hallik, Clinic of Anaesthesiology and Intensive Care, University of Tartu, L. Puusepa 8, Tartu 51014, Estonia; Phone: +3725055369; e-mail: maarja.hallik@ut.ee 
Copyright form disclosure: Drs. Hallik, Takkis, Veigure, Kipper, Starkopf, and Metsvaht institution's received funding from Estonian Research Council (PUT1197), and they received support for article research from the Estonian Research Council. Dr. Hallik received funding from the University of Tartu Foundation (scholarship from professor Lembit Allikmets' and Heino Kruse's foundations). Dr. Standing received support for article research from Research Councils UK (RCUK). The remaining authors have disclosed that they do not have any potential conflicts of interest. 


\section{ABSTRACT}

Objective: The postoperative course of patent ductus arteriosus (PDA) ligation is often complicated by postligation cardiac syndrome (PLCS), occurring in $10-45 \%$ of operated infants. Milrinone might prevent profound hemodynamic instability and improve the recovery of cardiac function in this setting. The present study aimed to describe the population pharmacokinetics (PK) of milrinone in premature neonates at risk of PLCS and give dosing recommendations.

Design: A prospective single group open label PK study.

Settings: Two tertiary care NICU-s: Tallinn Children's Hospital and Tartu University Hospital, Estonia.

Patients: 10 neonates with postmenstrual age (PMA) of 24.6 - 30.1 weeks and postnatal age of 527 days undergoing PDA ligation and at risk of PLCS, based on echocardiographic assessment of left ventricular output of less than $200 \mathrm{ml} / \mathrm{kg} / \mathrm{min} 1$ hour after the surgery.

Interventions: Milrinone at a dose of $0.73 \mu \mathrm{g} / \mathrm{kg} / \mathrm{min}$ for 3 hours followed by $0.16 \mu \mathrm{g} / \mathrm{kg} / \mathrm{min}$ for 21 hours. Four blood samples from each patient for milrinone plasma concentration measurements were collected.

Measurements and main results: Concentration-time data of milrinone were analyzed with nonlinear mixed-effects software (NONMEM version 7.3). Probability of target attainment (PTA) simulations gave a dosing schedule that maximally attains concentration targets of 150-250 $\mu \mathrm{g} / \mathrm{L}$. Milrinone PK was described by a one-compartmental linear model with allometric scaling to bodyweight and an age maturation function of glomerular filtration rate. Parameter estimates for a patient with the median weight were $0.350(\mathrm{~L} / \mathrm{h})$ for clearance and $0.329(\mathrm{~L})$ for volume of distribution. The best PTA was achieved with a loading dose of $0.50 \mu \mathrm{g} / \mathrm{kg} / \mathrm{min}$ for 3 hours followed by $0.15 \mu \mathrm{g} / \mathrm{kg} / \mathrm{min}$ (PMA<27 weeks) or $0.20 \mu \mathrm{g} / \mathrm{kg} / \mathrm{min}$ (PMA $\geq 27$ weeks).

Conclusions: Population PK modeling and simulations suggest a slow loading dose followed by maintenance infusion to reach therapeutic milrinone plasma concentrations within the timeframe of the PLCS. 


\section{INTRODUCTION}

Patent ductus arteriosus (PDA) management in preterm infants has been controversial over the decades. Today no consensus exists on the definition of hemodynamically significant PDA and it remains difficult to identify patients most likely to benefit from surgical duct closure. Observational studies show 10 $21 \%$ incidence of surgical closure $(1-4)$.

The postoperative course is complicated by acute cardiorespiratory deterioration or postligation cardiac syndrome (PLCS) in 10-45\% of operated infants $(5-8)$. The mechanisms behind postligation hemodynamic instability are complex and likely involve both, myocardial dysfunction and vascular tone dysregulation $(9,6)$. PLCS typically occurs between 6 to 12 hours after surgery $(7,10)$, providing a window for early (preventive) intervention (11). However, information on pre- and postoperative factors that can predict postligation cardiovascular compromise is scarce. In one retrospective analysis of targeted neonatal echocardiography in 62 infants undergoing PDA ligation, left ventricular output (LVO) $<200 \mathrm{ml} / \mathrm{kg} / \mathrm{min}$ at 1 hour after PDA ligation appeared a sensitive predictor of systemic hypotension and need for inotropes (11).

Milrinone is a selective phosphodiesterase type III inhibitor with positive inotropic and vasodilator ('inodilator') effect. Both effects are independent of beta- adrenergic stimulation (12). Milrinone has been found to prevent respiratory deterioration and hemodynamic instability and improve the recovery of cardiac function after surgical PDA closure $(11,13,14)$, although this finding has not been uniformly confirmed $(15,16)$. Suboptimal dosing has been suggested as possible reason for the variable efficacy (16). This idea is supported 
by our previous simulation study, aiming to optimize milrinone dosing regimen for current prospective clinical evaluation (17). Early pharmacokinetic (PK) studies in healthy subjects confirmed that milrinone is predominately eliminated by renal excretion with a fraction excreted unchanged of approximately $80 \%$ (12). To the best of our knowledge the PK of milrinone has not been described in preterm neonates undergoing PDA ligation surgery. Data from the first days of life in term (18) and very preterm neonates (19) or pediatric (mostly open heart cardiac surgery) population (20 - 23) may not be directly applicable to older preterm neonates, due to rapid changes in physiology and renal function maturation during the first weeks of life and/or after open heart cardiac surgery (23). Therefore, the prior simulation study (17) and the present study were undertaken to describe the population PK of milrinone in premature neonates at risk of PLCS with the aim to develop dosing recommendations for this specific age group.

\section{MATERIALS AND METHODS}

The study was approved by the Ethics Committee of the University of Tartu, and registered at the EU Clinical Trials Register under number 2015-000486-31.

A prospective two-center study was performed in the neonatal intensive care units in Tallinn Children's Hospital, Tallinn, Estonia and Tartu University Hospital, Tartu, Estonia. All neonates and infants up to 90 days of age requiring PDA ligation during the study period (June 2015 to October 2017), who had arterial and/or central venous line in place on clinical indication, were screened 
for eligibility. Patients with renal failure (defined as renal replacement therapy or serum creatinine $>100 \mu \mathrm{mol} / \mathrm{l}$ or oliguria $<0.5 \mathrm{ml} / \mathrm{kg} / \mathrm{min}$ for at least 6 hours), major congenital malformation or known metabolic disease, hypersensitivity or other contraindication to milrinone, expected survival of less than 72 hours, and patients recruited in another clinical trial of medical product, were excluded. Written informed consent was signed by parent(s) or guardian(s) before the study inclusion.

\section{Study drug administration and PK sampling}

Milrinone was started in infants at risk of PLCS, based on echocardiographic assessment of LVO of less than $200 \mathrm{ml} / \mathrm{kg} / \mathrm{min} 1$ hour after the end of PDA surgery (11). Milrinone (Corotrope $1 \mathrm{mg} / \mathrm{ml}$, Sanofi-Aventis France) was diluted with $0.9 \% \mathrm{NaCl}$ to a concentration of $15 \mu \mathrm{g} / \mathrm{ml}$ within $20 \mathrm{~min}$ before administration. A loading dose of $0.73 \mu \mathrm{g} / \mathrm{kg} / \mathrm{min}$ over 3 hours was followed by maintenance infusion of $0.16 \mu \mathrm{g} / \mathrm{kg} / \mathrm{min}$ for 21 hours, according to the prior simulation study results (17). Milrinone infusion rate could be changed or discontinued at the discretion of the treating physician. To ensure adequate intravascular volume, all infants received a bolus of $9 \mathrm{ml} / \mathrm{kg}$ of normal saline over three hours with the milrinone loading dose infusion. Further hemodynamic support with fluid boluses and inotropes was provided according to the routines of the unit.

Blood samples of $0.3 \mathrm{ml}$ were collected from an indwelling arterial line into $\mathrm{Na}-$ heparin vials at the end of loading infusion (3h), at the end of maintenance 
infusion ( $24 \mathrm{~h}$ ) and twice after the end of treatment (28 h, $36 \mathrm{~h})$. Actual blood collection time was recorded with the precision of the nearest minute. Blood was centrifuged immediately and stored at $-80^{\circ} \mathrm{C}$ (up to $12 \mathrm{~h}$ storage at $-20^{\circ} \mathrm{C}$ prior to transfer to $-80{ }^{\circ} \mathrm{C}$ was accepted). Milrinone concentrations were measured by ultra-high performance liquid chromatography coupled to tandem mass spectrometry (UHPLC-MS/MS; Supplemental digital content 1).

\section{Patient monitoring}

All PDA ligation surgeries were performed in NICU by one experienced surgeon, using intravenous anesthesia with ketamine, fentanyl and atracurium. Echocardiography was done 1 hour before PDA surgery, 1 hour after duct ligation, 3 and 24 hours after the start of study medication infusion. Studies were performed by 4 cardiologists, using the Vivid 7 Dimension or Vivid E9 cardiovascular ultrasound system (GE Healthcare, USA) with 10 or $12 \mathrm{MHz}$ transducers, respectively. LVO was calculated by obtaining the pulsed wave Doppler blood velocity in the aortic root and measuring the diameter of the aortic root (24).

Echocardiography recordings from 3 infants attained by 3 different cardiologists were re-analyzed by one observer (TJ) for intra- and inter-observer variability, according to a recent recommendation (25).

Heart rate, arterial blood pressure and other vital signs were monitored with IntelliVue MP30, M70 or MX800 patient monitors (Philips Medical Systems, The Neatherlands) and recorded with $2.5 \mathrm{sec}$ intervals by BedBase software 
(University Medical Center Utrecht, the Netherlands) starting from 1 hour prior to PDA surgery until the end of treatment with study medication. All neonates were monitored for adverse events for 7 days after the end of treatment with study medication.

\section{$\underline{\text { PK analysis }}$}

Concentration-time data were analyzed with nonlinear mixed-effects software NONMEM version 7.3 (ICON Development Solutions, MD, USA). The first-order conditional estimation method with interaction was used. One- and twocompartment linear structural models were considered. An additive residual error model, a proportional residual error model, and a combination of the two were tested. Models were compared by objective function value (OFV), for a nested model a parameter was added if their inclusion resulted in improvement of OFV value $>3.84(P<0.05$ by likelihood ratio test for 1 degree of freedom). Allometric scaling was used a priori to standardize PK parameters to population mean bodyweight, and a maturation function, describing the maturation of the glomerular filtration rate (GFR) with postmenstrual age (PMA) was applied to scale clearance:

$$
\text { maturation function }=\frac{P M A^{\text {Hill }}}{P M A_{50}^{H i l l}+P M A^{H i l l}}
$$

where Hill is the sigmoidicity coefficient and PMA50 is the PMA when the maturation of the GFR reaches $50 \%$ of adult values (26). Fixed parameters from a previous study (27) were used to scale clearance (CL) and volume of 
distribution (Vd). As in previous neonatal studies, allometric exponents were fixed to 0.632 for CL and 1 for $\operatorname{Vd}(28,29)$.

Other patient covariates (such as sex, Apgar, albumin level, fluid intake, cardiac output and co-administration with dopamine or dobutamine) were tested for correlation with model parameters.

To evaluate the model, population and individual predicted vs. observed milrinone concentration measurements, and conditional weighted residual error vs. time plots were used. A nonparametric bootstrap with 2000 replicates using the software Perl speaks NONMEM (PsN) was undertaken to assess the robustness of parameter estimates to changes in data. A visual predictive check (VPC) was performed to assess the simulation properties of the final model.

\section{Probability of target attainment (PTA) simulations}

PTA simulations aimed to develop a dosing schedule that maximally attains milrinone concentration within the pre-specified target range of $150-250 \mu \mathrm{g} / \mathrm{l}$ by the 6th postoperative hour for the majority of patients (17), as PLCS has been found to occur $6-12 \mathrm{~h}$ after ligation $(6,7)$. All simulations were conducted using $\mathrm{R}$ software version 3.3.3. (30)

Patient covariate (PMA and weight) data from all PDA ligation patients treated in the study units between 2013-2017 were bootstrapped to 1000 samples. Next, patient PK parameters were simulated using parameter equations and variability estimates from the PK model. Milrinone time-concentration curves were simulated with doses ranging from 0 to $1 \mu \mathrm{g} / \mathrm{kg} / \mathrm{min}$, with a step of 0.05 
$\mu \mathrm{g} / \mathrm{kg} / \mathrm{min}$. The dosing scheme consisted of a 3-hour loading dose immediately followed by a 21-hour maintenance infusion, as justified in our prior study (17). An optimal dose maximized the mean of PTA values obtained at 3, 6, 12, 18 and 24 hours of treatment. The PTA estimates targeted within 150 and $250 \mu \mathrm{g} / \mathrm{l}$ were adjusted with the probability of concentrations above $300 \mu \mathrm{g} / \mathrm{l}$, to minimize possible side effects.

A second set of analogous simulations additionally assessed the effect of PMA on target attainment. Patient population was divided by a PMA breakpoint into two subgroups of different maintenance doses. The optimization searched for a combination of parameter values yielding maximal PTA. All simulation details are presented in supplemental digital content 2 .

\section{RESULTS}

During the study period 21 neonates underwent PDA ligation surgery, 14 of them were recruited into the study (Figure 1). The reasons for exclusion were participation in another clinical study ( 3 patients), absent parental consent ( 2 patients) and renal failure with creatinine $>100 \mu \mathrm{mol} / \mathrm{l}(2$ patients).

Ten out of 14 patients had $\mathrm{LVO}<200 \mathrm{ml} / \mathrm{kg} / \mathrm{min}$ and were treated with milrinone according to the study protocol. No dose adjustments or preliminary discontinuation of therapy was performed. Mean PMA and weight on the day of PDA ligation were 27.4 weeks and 857.3 g, respectively, and all but three required invasive respiratory support (Table 1). 


\section{Milrinone plasma concentrations}

In total 40 time-concentration data points, 4 from each patient were available for PK analysis (Supplemental digital content 3). The median (range) plasma concentrations of the drug at 3, 24, 28 and $36 \mathrm{~h}$ were 279.7 (213.6 - 366.2), 186.7 (84.3 - 361.0), $105.1(27.1-227.3)$ and $45.4(3.0$ - 113.3) $\mu \mathrm{g} / \mathrm{l}$, respectively.

\section{$\underline{\text { PK model }}$}

A one-compartmental linear structural model with proportional error model was chosen to describe the population $\mathrm{PK}$ data $(\triangle \mathrm{OFV}=1$ with two-compartmental model). Adding allometric scaling to bodyweight and maturation function of GFR of the model parameters to the structural model reduced the OFV from 291.9 to 273.1. The final milrinone population PK model parameters are described in equations:

$$
\begin{gathered}
C L=\theta_{C L} \cdot\left(\frac{W D 1}{857.3}\right)^{0.632} \cdot \frac{P M A^{3.4}}{47.7^{3.4}+P M A^{3.4}} \\
V d=\theta_{V d} \cdot\left(\frac{W D 1}{857.3}\right)^{1}
\end{gathered}
$$

where CL is clearance, Vd is volume of distribution, $\Theta_{C L}$ and $\Theta_{V d}$ are the population typical values for clearance and volume of distribution, respectively, 
WD1 is body weight in grams and PMA the postmenstrual age in weeks on the day of PDA ligation.

Population and individual predicted vs. observed and residual error plots of milrinone plasma concentrations from the final model are shown on Figure 2, VPCs for the model on Figure 3. The final population mean (coefficient of variation) parameter estimates for CL and Vd were $0.350 \mathrm{~L} / \mathrm{h} / 857.3 \mathrm{~g}(11.6 \%)$ and $0.329 \mathrm{~L} / 857.3 \mathrm{~g}$ (32.6\%), respectively. Comparison with bootstrap results demonstrates that the model is robust to changes in data (Table 2).

\section{Dose optimization and PTA}

Demographic data from a total of 52 patients with mean (range) PMA and bodyweight of $27.6(23.3-37.3)$ weeks and $875.5(500-2351)$ g, respectively, underwent PDA ligation during the period of 2013-2017 and were included in dose optimization simulations. The best PTA was achieved with a 3-hour loading dose of $0.50 \mu \mathrm{g} / \mathrm{kg} / \mathrm{min}$ followed by maintenance infusion rate of 0.15 $\mu \mathrm{g} / \mathrm{kg} / \mathrm{min}$ (Supplemental digital content 4). Variation of maintenance doses by PMA improved PTA from 0.561 to 0.589 with the PMA threshold of 27 weeks and maintenance doses of 0.15 and $0.20 \mu \mathrm{g} / \mathrm{kg} / \mathrm{min}$, in $\mathrm{PMA}<27$ and $\mathrm{PMA} \geq 27$ group respectively (Figure 4 and Supplemental digital content 5). 


\section{Cardiac output, milrinone side effects and adverse events}

None of the study patients developed PLCS. By $24 \mathrm{~h}$ of therapy LVO improved in all but two patients by an average (SD) of 54 (64) $\mathrm{ml} / \mathrm{kg} / \mathrm{min}$ (paired Wilcoxon test $\mathrm{p}=0.037$; supplemental digital content 6). Intra- and inter-observer variability (mean \pm SD) of LVO measurements were $10 \pm 5 \mathrm{ml} / \mathrm{kg} / \mathrm{min}(6 \pm 4 \%)$ and $37 \pm 43 \mathrm{ml} / \mathrm{kg} / \mathrm{min}(15 \pm 16 \%)$, respectively (Supplemental digital content 7). Tachycardia (HR >200 $\mathrm{min}^{-1}$ ) registered in 3 patients during milrinone therapy with cumulative time over the threshold of 6,3 and $37 \mathrm{~min}$, respectively, triggered no change in treatment. Arterial hypotension (MAP $<30 \mathrm{mmHg}$ ) was registered in 6 patients with cumulative time under the threshold of $21,327,183$, 13, 101 and $30 \mathrm{~min}$, respectively. Vasoactive treatment was started in two cases, one patient was already on dopamine with no increase in dose during milrinone treatment. One patient with thrombocytopenia (platelet count $<100 \times 10^{9} \mathrm{~L}^{-1}$ ) present prior to PDA ligation was treated with platelet transfusion.

\section{DISCUSSION}

The study provides milrinone population PK model and dosing recommendations for preterm neonates to prevent hemodynamic and respiratory deterioration after PDA ligation. The dose recommendations are different from the existing suggestions, derived either from data obtained in preterm neonates in very first days of their life, or from infants undergoing heart surgery. 
Consistent with previous data, suggesting the effect of bodyweight and renal function maturation $(19,21-23,31)$ on the PK of milrinone, a onecompartmental model with allometric scaling to population mean bodyweight and maturation function of elimination described the data best. Scaling PK parameters to size and PMA has been proposed as a standard for describing PK in a range of age groups including preterm neonates (32), and fixing the age and maturation parameters in neonatal studies with limited age and weight ranges is also common $(28,29,33)$. Indeed, the principle of delineating size from other potentially important covariates has been applied in many pediatric settings including immunology (34). As milrinone is eliminated primarily by kidneys (35), we chose maturation function of GFR (27) for elimination. In order to compare our results with other similar studies not using this covariate structure, we chose to standardize PK parameters to the population mean weight (857.3 g).

Considering the small homogenous population and dosing recommendations for the specific indication, this approach was preferred over the $70 \mathrm{~kg}$ standard weight (26). The uncertainty in predicting mature clearance, based on data only from neonatal populations with age below maturation half time (PMA50 $=47.7$ weeks in the model) has been pointed out previously by Anderson and Holford (36).

The lower population mean Vd (0.329 vs. $0.512 \mathrm{~L})$ and higher CL ( 0.350 vs. 0.035 $\mathrm{L} / \mathrm{h}$ ) found in our study compared to that described previously in preterm infants studied within the first three days of life (19) is probably explained by different postnatal age of the study populations. Significant reduction in total body water (accompanied by proportional weight loss) within the first three to 
four days of life (37) results in lower Vd for water soluble agents (38). All but one of our patients were over one week of age, when this reduction in total body water has effectively taken place. Similarly, GFR doubles within the first week of life, while significant maturation of the renal secretion function occurs only over the first 3-4 weeks of life (39). Accordingly, the dosing of milrinone, based on our prior simulation study (17) using milrinone population PK model developed in preterm neonates within the first days of life (19), resulted in higher than expected loading and lower maintenance concentrations in current study population. This underlines the need for prospective validation and further refining of dosing regimens, recommended solely based on simulation studies, especially in populations, where major physiological changes in organ function and maturation take place within weeks, like preterm neonates.

Similar to our approach, a physiology based pharmacokinetic drug-disease model study has suggested the need for milrinone loading infusion to ensure fast achievement of therapeutic plasma concentrations (31). Previously, Jain et al. have found a continuous infusion of $0.33 \mu \mathrm{g} / \mathrm{kg} / \mathrm{min}$ over $24 \mathrm{~h}$ to be effective in the prevention of PCLS (11). However, in a latter retrospective cohort of 86 patients six out of seven, who developed PLCS, were receiving milrinone according to this regimen. The authors suggested insufficient dose of milrinone to offload the $\mathrm{LV}$ and prevent late deterioration in myocardial performance as a possible reason for the evolution of low LVO (16). Our results support this idea. With milrinone loading infusion, targeting therapeutic plasma concentrations within $3 \mathrm{~h}$ from start of infusion, followed by a $21 \mathrm{~h}$ maintenance infusion, none of the 10 patients treated on similar indication ( $\mathrm{LVO}<200 \mathrm{ml} / \mathrm{kg} / \mathrm{min}$ ), 
developed PLCS. Yet, this finding should be interpreted with caution, as the study lacks statistical power to draw firm conclusions on clinical efficacy.

In order to minimize the risk of negative hemodynamic effects, we chose a lower target concentration in our in silico simulation study (150-200 $\mu \mathrm{g} / \mathrm{l})$ (17) compared to a previous population $\mathrm{PK}$ and dosing recommendation study by Paradisis et al. (180-300 $\mu \mathrm{g} / \mathrm{l})$ (19). Nevertheless, measured plasma milrinone concentrations during the treatment period were similar in current study and the randomized placebo controlled study by Paradisis et al. (40), $84-366$ and 95 - $407 \mu \mathrm{g} / \mathrm{l}$, respectively. Tachycardia and low blood pressure were the most common hemodynamic side effects in both studies. Paradisis et al. reported significantly higher HR and lower BP, but no difference in the incidence of hypotension, defined as mean $\mathrm{BP}<24 \mathrm{~mm} \mathrm{Hg}$ for more than 30 minutes or a drop in mean BP $>20 \%$ within 2 hours of commencing the infusion or in the number treated with additional inotropes, compared to placebo (40). In our study tachycardia did not trigger dose change or discontinuation of milrinone therapy, low blood pressure was present in 6 cases requiring treatment in two. In both cases $3 \mathrm{~h}$ milrinone concentrations exceeded $300 \mu \mathrm{g} / \mathrm{l}$ and the neonates had PMA $<27$ weeks. According to this scarce data, we adjusted our optimal dose finding simulations to avoid concentrations above $300 \mu \mathrm{g} / \mathrm{l}$ and included maturation of CL with PMA.

The PMA dependent CL of milrinone suggested improved concentration target attainment when differentiating maintenance doses according to PMA. Indeed, application of higher maintenance dose ( 0.20 instead of $0.15 \mu \mathrm{g} / \mathrm{kg} / \mathrm{min}$ ) for neonates with $\mathrm{PMA} \geq 27$ weeks reduced the proportion of patients with 
simulated plasma concentrations below the target, however, at the cost of higher proportion exceeding $300 \mu \mathrm{g} / \mathrm{l}$. According to the PTA simulation results, we would recommend the dosing regimen of $0.5 \mu \mathrm{g} / \mathrm{kg} / \mathrm{min} 3 \mathrm{~h}$ loading followed by $0.15 \mu \mathrm{g} / \mathrm{kg} / \mathrm{min}$ maintenance infusion for infants PMA $<27$ weeks and 0.5 $\mu \mathrm{g} / \mathrm{kg} / \mathrm{min} 3 \mathrm{~h}$ loading followed by $0.2 \mu \mathrm{g} / \mathrm{kg} / \mathrm{min}$ for infants $\mathrm{PMA} \geq 27$ weeks. The PD effect on blood flow and effectiveness of preventing PLCS of this dosing scheme will be the objective of future studies.

This study has several limitations. First, the small number of patients precluded the exploration of the impact of additional patient characteristics potentially affecting the PK of milrinone, including prior ibuprofen therapy and the status of renal function. Similarly, we cannot provide full PD analysis. However, considering the homogenous population, we believe that the study adds new information to improve the dosing of milrinone for the specific indication of PLCS prevention in preterm neonates without severe renal function impairment.

\section{CONCLUSIONS}

Pediatric PK data need to be collected in populations where physiological changes take place over short time periods. Rapid change in total body water content and GFR in the first weeks of a preterm infants life influences significantly the PK of milrinone. Age appropriate PK analysis and dosing recommendations will allow better-targeted efficacy and safety assessments. Slow loading dose of milrinone holds the advantage of reaching adequate plasma concentrations within the therapeutic window prior to the emergence of PLCS. 


\section{ACKNOWLEDGEMENTS}

This study was supported by the Estonian Research Council (PUT1197, IUT34-4).

M.H was supported by The University of Tartu Foundation (scholarship from professor Lembit Allikmets' and Heino Kruse’s foundations). J.F. S. was supported by the NIHR Biomedical Research Centre at Great Ormond Street Hospital for Children NHS Foundation Trust and University College London, and received a UK Medical Research Council fellowship (MR/M008665/1). The authors thank doctor Natan Toomas Aro for kind collaboration and professor Irja Lutsar for valuable comments and support. 


\section{REFERENCES}

1. Hagadorn JI, Brownell EA, Trzaski JM, et al: Trends and variation in management and outcomes of very low-birth-weight infants with patent ductus arteriosus. Pediatr Res 2016; 80(6):785-792

2. Lokku A, Mirea L, Lee SK, et al: Trends and outcomes of patent ductus arteriosus treatment in very preterm infants in Canada. Am J Perinatol $2016 ; 34: 441-50$

3. Weinberg JG, Evans FJ, Burns KM, et al: Surgical ligation of patent ductus arteriosus in premature infants: trends and practice variation. Cardiol Young 2016; 26(6):1107-14

4. Boghossian NS, Do BT, Bell EF, et al; Eunice Kennedy Shriver National Institute of Child Health and Human Development Neonatal Research Network: Efficacy of pharmacologic closure of patent ductus arteriosus in small-for-gestational-age extremely preterm infants. Early Hum Dev 2017; $113: 10-17$

5. Ulrich TJB, Hansen TP, Reid KJ, et al: Post-ligation cardiac syndrome is associated with increased morbidity in preterm infants. J Perinatol 2018; 38(5):537-542

6. Noori S, Friedlich P, Seri I, et al: Changes in myocardial function and hemodynamics after ligation of the ductus arteriosus in preterm infants. $J$ Pediatr 2007; 150(6):597-602

7. McNamara PJ, Stewart L, Shivananda SP, et al: Patent ductus arteriosus ligation is associated with impaired left ventricular systolic performance 
in premature infants weighing less than 1000 g. J Thorac Cardiovasc Surg $2010 ; 140: 150-7$

8. Noori S, McNamara P, Jain A, et al; PDA Ligation/Hypotension Trial Investigators: Catecholamine-resistant hypotension and myocardial performance following patent ductus arteriosus ligation. J Perinatol 2015; $35(2): 123-7$

9. El-Khuffash AF, Jain A, McNamara PJ: Ligation of the patent ductus arteriosus in preterm infants: understanding the physiology. J Pediatr $2013 ; 162(6): 1100-6$

10. Teixeira LS, Shivananda SP, Stephens D, et al: Postoperative cardiorespiratory instability following ligation of the preterm ductus arteriosus is related to early need for intervention. J Perinatol 2008; 28:803-10

11. Jain A, Sahni M, El-Khuffash A, et al: Use of targeted neonatal echocardiography to prevent postoperative cardiorespiratory instability after patent ductus arteriosus ligation. J Pediatr 2012; 160:584-89

12. Stroshane RM, Koss RF, Biddlecome CE, et al: Oral and intravenous pharmacokinetics of milrinone in human volunteers. J Pharm Sci 1984; 73(10):1438-41

13. El-Khuffash AF, Jain A, Weisz D, et al: Assessment and treatment of post patent ductus arteriosus ligation syndrome. J Pediatr 2014; 165:46-52

14. Sehgal A, Francis JV, Lewis AI: Use of milrinone in the management of haemodynamic instability following duct ligation. Eur J Pediatr 2011; 170:115-9 
15. Halliday M, Kavarana M, Ebeling M, et al: Milrinone use for hemodynamic instability in patent ductus arteriosus ligation. J Matern Fetal Neonatal Med 2017; 30(5):529-533

16. Ting JY, Resende M, More K, et al: Predictors of respiratory instability in neonates undergoing patient ductus arteriosus ligation after the introduction of targeted milrinone treatment. J Thorac Cardiovasc Surg 2016; 152(2):498-504

17. Hallik M, Tasa T, Starkopf J, et al: Dosing of Milrinone in Preterm Neonates to Prevent Postligation Cardiac Syndrome: Simulation Study Suggests Need for Bolus Infusion. Neonatology 2017; 111(1):8-11

18. McNamara PJ, Shivananda SP, Sahni M, et al: Pharmacology of milrinone in neonates with persistent pulmonary hypertension of the newborn and suboptimal response to inhaled nitric oxide. Pediatr Crit Care Med 2013 ; 14(1):74-84

19. Paradisis M, Jiang X, McLachlan AJ, et al: Population pharmacokinetics and dosing regimen design of milrinone in preterm infants. Arch Dis Child Fetal Neonatal Ed 2007; 92:F204-F209

20. Lindsay CA, Barton P, Lawless S, et al: Pharmacokinetics and pharmacodynamics of milrinone lactate in pediatric patients with septic shock. J Pediatr 1998; 132(2):329-34

21. Ramamoorthy C, Anderson GD, Williams GD, et al: Pharmacoki- netics and side effects of milrinone in infants and children after open heart surgery. Anesth Analg 1998; 86:283-289 
22. Bailey JM, Hoffman TM, Wessel DL, et al: A population pharmacokinetic analysis of milrinone in pediatric patients after cardiac surgery. $J$ Pharmacokinet Pharmacodyn 2004; 31(1):43-59

23. Zuppa AF, Nicolson SC, Adamson PC, et al: Population pharmacokinetics of milrinone in neonates with hypoplastic left heart syndrome undergoing stage I reconstruction. Anesth Analg 2006; 102:1062-1069

24. El-Khuffash AF, Jain A, Dragulescu A, et al: Acute changes in myocardial systolic function in preterm infants undergoing patent ductus arteriosus ligation: a tissue Doppler and myocardial deformation study. J Am Soc Echocardiogr 2012; 25(10):1058-67

25. Popović ZB, Thomas JD: Assessing observer variability: a user's guide. Cardiovasc Diagn Ther 2017; 7(3):317-324

26. Germovsek E, Barker CI, Sharland M, et al: Scaling clearance in paediatric pharmacokinetics: All models are wrong, which are useful? Br J Clin Pharmacol 2017; 83(4):777-790

27. Rhodin MM, Anderson BJ, Peters AM, et al: Human renal function maturation: a quantitative description using weight and postmenstrual age. Pediatr Nephrol 2009; 24(1):67-76

28. Germovsek E, Kent A, Metsvaht T, et al: Development and Evaluation of a Gentamicin Pharmacokinetic Model That Facilitates Opportunistic Gentamicin Therapeutic Drug Monitoring in Neonates and Infants. Antimicrob Agents Chemother. 2016; 60(8):4869-77

29. Germovsek E Lutsar I, Kipper K, et al; NeoMero Consortium: Plasma and CSF pharmacokinetics of meropenem in neonates and young infants: results from the NeoMero studies. J Antimicrob Chemother 2018 
30. R Core Team: R: A Language and Environment for Statistical Computing. Vienna, R Foundation for Statistical Computing, 2014. http://www.Rproject.org/. Accessed March 24, 2017

31. Vogt W: Evaluation and optimisation of current milrinone prescribing for the treatment and prevention of low cardiac output syndrome in paediatric patients after open heart surgery using a physiology-based pharmacokinetic drug-disease model. Clin Pharmacokinet 2014; 53:51-72

32. Holford N, Heo YA, Anderson B: A pharmacokinetic standard for babies and adults. J Pharm Sci 2013; 102: 2941-52

33. Padari H, Metsvaht T, Germovsek E, et al: Pharmacokinetics of Penicillin G in Preterm and Term Neonates. Antimicrob Agents Chemother 2018 Apr $26 ; 62(5)$

34. Hoare RL, Veys P, Klein N, et al: Predicting CD4 T-Cell Reconstitution Following Pediatric Hematopoietic Stem Cell Transplantation. Clin Pharmacol Ther 2017; 102(2):349-357

35. Young RA, Ward A: Milrinone. A preliminary review of its pharmacological properties and therapeutic use. Drugs. 1988; 36(2):15892

36. Anderson BJ, Holford NH: Tips and traps analyzing pediatric PK data. Paediatr Anaesth. 2011 Mar;21(3):222-37

37. Bauer K, Versmold H: Postnatal weight loss in preterm neonates less than $1,500 \mathrm{~g}$ is due to isotonic dehydration of the extracellular volume. Acta Paediatr Scand Suppl 1989; 360:37-42

38. Pacifici GM: Clinical pharmacokinetics of aminoglycosides in the neonate: a review. Eur J Clin Pharmacol. 2009; 65(4):419-27 
39. Chen N, Aleksa K, Woodland C, et al: Ontogeny of drug elimination by the human kidney. Pediatr Nephrol 2006; 21:160-168

40. Paradisis M, Evans N, Kluckow M, et al: Randomized trial of milrinone versus placebo for prevention of low systemic blood flow in very preterm infants. J Pediatr 2009; 154(2):189-95 


\section{FIGURE LEGENDS}

Figure 1. Flowchart of the patient recruitment and treatment decision. LVO - left ventricular output.

Figure 2. Basic goodness-of-fit plots of the final PK model: (A) observed versus population predicted milrinone concentrations, (B) observed versus individual predicted milrinone concentrations, (C) absolute value of individual weighted residuals (|iWRES|) versus individual predictions, (D) conditional weighted residuals over time.

Figure 3. Visual predictive check (VPC) of 1,000 simulated concentration-time data sets from the final model. Open circles represent the observations, solid line the 50th, dashed lines the 2.5th and 97.5th percentiles, shaded areas the 95\% confidence intervals of the corresponding predicted milrinone concentrations.

Figure 4. Simulated concentration-time curves: (A) 3-hour $0.5 \mu \mathrm{g} / \mathrm{kg} / \mathrm{min}$ loading dose followed by a 21-hour maintenance dose of $0.15 \mu \mathrm{g} / \mathrm{kg} / \mathrm{min}$, (B) 3hour $0.5 \mu \mathrm{g} / \mathrm{kg} / \mathrm{min}$ loading dose followed by a 21-hour maintenance dose of $0.15 \mu \mathrm{g} / \mathrm{kg} / \mathrm{min}$ in subjects under 27 weeks of PMA and $0.2 \mu \mathrm{g} / \mathrm{kg} / \mathrm{min}$ in subjects with $P M A \geq 27$ weeks. The lines show $2.5 \%, 50 \%$ and $97.5 \%$ percentiles of the simulated concentrations, shaded areas show bootstrapped $95 \%$ confidence intervals. 
TABLES

Table 1. Demographics and clinical data of the treated patients

Table 2. Final parameter estimates with uncertainty from NONMEM output file and from the bootstrap analysis

\section{SUPPLEMENTAL DIGITAL CONTENTS}

1. Description of milrinone plasma concentration measurement method

2. Detailed description of probability of target attainment (PTA) simulations

3. Measured milrinone plasma concentrations

4. Optimization results of loading and maintenance phase doses

5. Optimization results for PMA threshold for different maintenance doses

6. Left ventricular output changes during milrinone treatment

7. Intra- and inter-observer variability of left ventricular output measurements 